\title{
Endoscopic ultrasound-guided detection and internal drainage of a closed gastro- cutaneous fistula after bariatric surgery
}
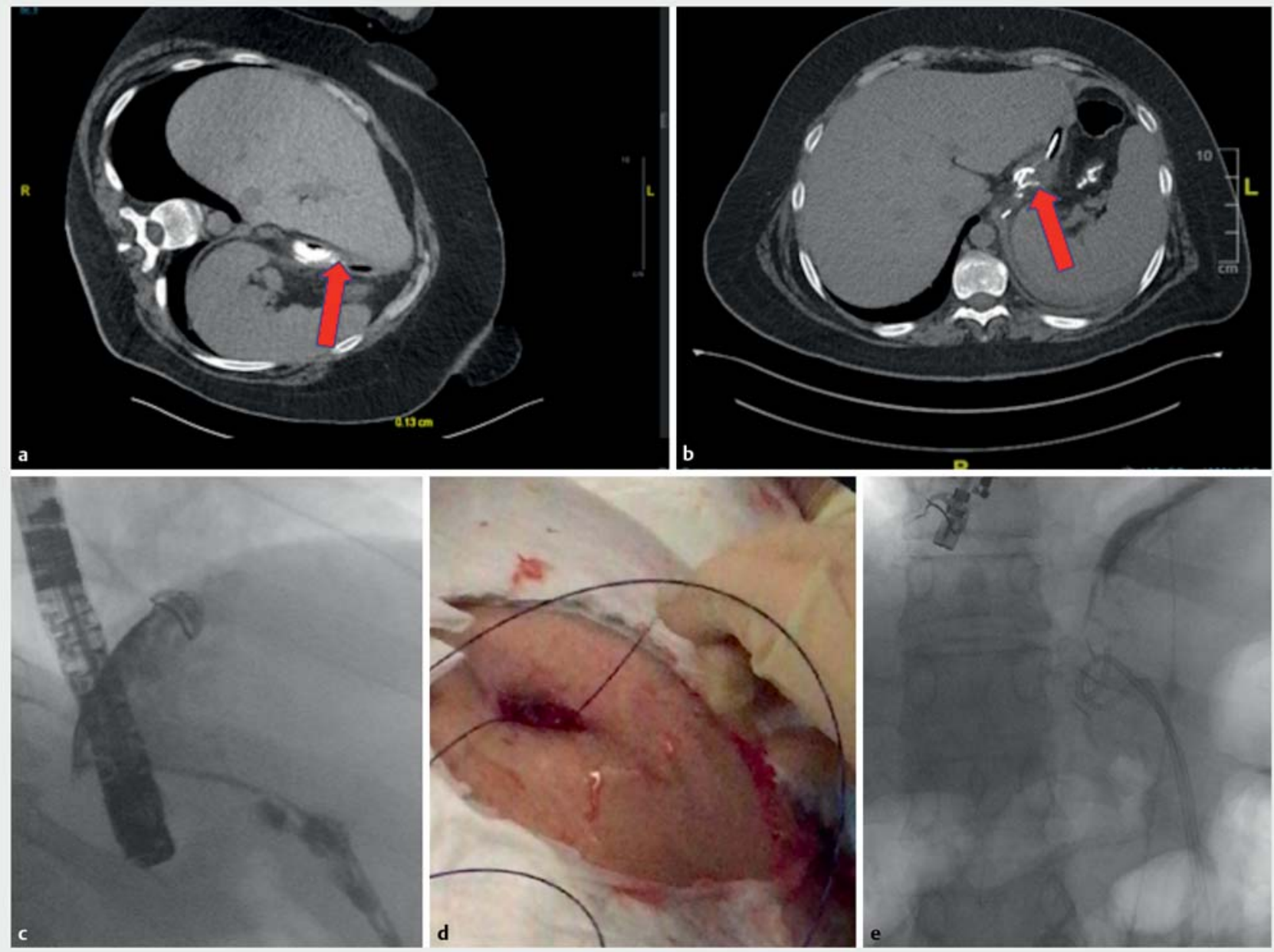

Fig. 1 Endoscopic ultrasound (EUS)-guided drainage of a closed fistula after bariatric surgery. a Contrast swallow computed tomography scan detected the fistula tract (arrow). b Result after the procedure; pigtail stents in place. c Puncture under EUS guidance. $\mathbf{d}$ Cutaneous aspect with large defect. e End of procedure; pigtail stents in place (arrow).

Endoscopic drainage of fistulas with plastic stents after bariatric surgery is a minimally invasive technique with high success and low morbidity rates [1,2]. However, it is sometimes difficult to find or cannulate the internal orifice of the fistula owing to limited maneuverability, a relatively small opening, tortuous trajectory or even spontaneous closure of the orifice. In such cases, endoscopic ultrasound (EUS)-guided puncture can be an option for draining various fluid collec- tions in the abdominal cavity $[3,4]$, by finding the internal orifice or by creating an additional trajectory to the collection [5].

We report the case of a 38-year-old patient with a postbariatric gastro-cutaneous fistula who was referred to our department for endoscopic drainage. Despite conservative therapy 3 months after a sleeve gastrectomy, the patient experienced continuous purulent cutaneous discharge of a peri-gastric collec- tion. Water-soluble contrast swallow computed tomography (CT) scan showed a gastro-cutaneous fistula originating at the upper part of the staple line of the sleeve gastrectomy ( $\mathbf{F i g . 1} \mathbf{a}$ ).

During the first endoscopy attempt, the gastric orifice was not visible despite injection of contrast via the cutaneous orifice. A second endoscopy was attempted and the fistula tract was detected endosonographically by injecting solution into the fistula through the cutaneous 


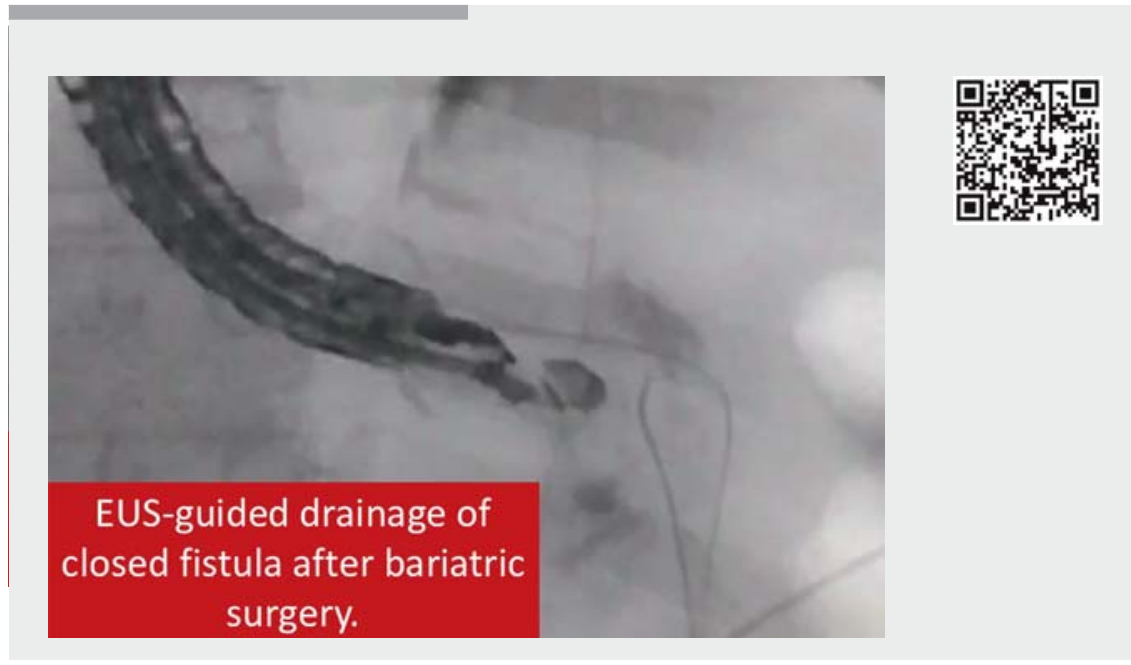

$\checkmark$ Video 1 Endoscopic ultrasound-guided drainage of a closed fistula after bariatric surgery. orifice. A 19-gauge needle was used to puncture the fistula tract and place a guidewire ( $\triangleright$ Fig. 1 c, d). Balloon dilation was performed to enlarge the entrance, and a second guidewire was placed. Consequently, two 7-Fr double-pigtail plastic drains were placed in the fistula tract ( $\triangleright$ Fig. 1 b, $\triangleright$ Video 1 ).

One week after the intervention, there was no purulent cutaneous discharge and the CT scan showed the stents in the fistula through the internal orifice, with no contrast extravasation; the fluid collection had decreased compared with previous imaging ( $\triangleright$ Fig. 1 e).

When the fistula orifice is not clearly visible or when it closes spontaneously, EUS procedures allow success in draining the fistula in a one-step procedure.

Endoscopy_UCTN_Code_TTT_1AS_2AC

\section{Competing interests}

None
The authors

Dora Lippai ${ }^{1,2}$, Alexandru Lupu ${ }^{2,3}$, Florian Rostain ${ }^{2}$, Jérôme Rivory ${ }^{2}$, Maud Robert ${ }^{4}$, Thierry Ponchon ${ }^{2,5}$, Mathieu Pioche ${ }^{2,5}$

1 2nd Department of Internal Medicine, Semmelweis University, Budapest, Hungary

2 Department of Endoscopy and Gastroenterology, Pavillon L, Edouard Herriot Hospital, Lyon, France

3 Department of Endoscopy and Gastroenterology, Fundeni Clinical Institute, Bucarest, Romania

4 Department of Bariatric and Digestive Surgery, Department of Endoscopy and Gastroenterology, Pavillon L, Edouard Herriot Hospital, Lyon, France

5 Inserm U1032 LabTau, Lyon, France

\section{Corresponding author}

\section{Mathieu Pioche, MD}

Endoscopy Unit - Digestive Disease Department, Pavillon L - Edouard Herriot Hospital, 69437 Lyon Cedex, France Fax: +33-4-72110147

mathieu.pioche@chu-lyon.fr
[1] Lorenzo D, Guilbaud T, Gonzalez JM et al. Endoscopic treatment of fistulas after sleeve gastrectomy: a comparison of internal drainage versus closure. Gastrointest Endosc 2018; 87: 429-437

[2] Bège $T$, Emungania $O$, Vitton $V$ et al. An endoscopic strategy for management of anastomotic complications from bariatric surgery: a prospective study. Gastrointest Endosc 2011; 73: 238 - 244

[3] Souto-Rodríguez R, Alvarez-Sánchez M-V. Endoluminal solutions to bariatric surgery complications: a review with a focus on technical aspects and results. World J Gastrointest Endosc 2017; 9: 105-126

[4] Alali A, Mosko J, May G et al. Endoscopic ultrasound-guided management of pancreatic fluid collections: update and review of the literature. Clin Endosc 2017; 50: 117-125

[5] Bouchard S, Eisendrath P, Toussaint E et al. Trans-fistulary endoscopic drainage for post-bariatric abdominal collections communicating with the upper gastrointestinal tract. Endoscopy 2016; 48: 809-816

\section{Bibliography}

DOI https://doi.org/10.1055/a-0631-8479

Published online: 19.6.2018

Endoscopy 2018; 50: E248-E249

(c) Georg Thieme Verlag KG

Stuttgart · New York

ISSN 0013-726X

\section{ENDOSCOPY E-VIDEOS}

https://eref.thieme.de/e-videos

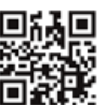

Endoscopy E-Videos is a free access online section, reporting on interesting cases and new techniques in gastroenterological endoscopy. All papers include a high quality video and all contributions are freely accessible online.

This section has its own submission website at https://mc.manuscriptcentral.com/e-videos 